\title{
ESTUDO DO COMPORTAMENTO VISUAL DA SINALIZAÇÃO ANAMÓRFICA
}

\author{
Erika Namimatsu Fukuyama, Claudemilson dos Santos.
}

Universidade do Oeste Paulista, Curso de Arquitetura e Urbanismo, Presidente Prudente, SP. Universidade Estadual Paulista, Presidente Prudente, SP. E-mail: erikanf.28@gmail.com

Agência de fomento: Programa de Iniciação Científica e Mestrado - PICME.

\section{RESUMO}

Esta pesquisa propõe uma analise do comportamento da sinalização de trânsito horizontal baseada na anamorfose conforme o deslocamento do condutor do veículo. O objetivo foi diagnosticar a viabilidade da sinalização com base em estudos matemáticos que apontaram a variação na altura da anamorfose em determinadas distâncias. Para a realização deste estudo foram elaboradas duas tabelas que apresentam, através dos cálculos, os resultados do comportamento da sinalização anamórfica e também um gráfico a partir desses valores para visualizar melhor essa variação. Os resultados apresentados no gráfico apontaram um aumento gradativo no tamanho da anamorfose e um aumento mais acentuado após o condutor atingir a distância de segurança. Além disso, pode ser observado que o comprimento da anamorfose será muito maior que o da sinalização padrão. É importante que haja outros estudos para analisar melhor a viabilidade deste tipo de sinalização de trânsito.

Palavras-chave: anamorfose, sinalização de trânsito horizontal, comportamento visual, comparativos, sinalização anamórfica.

\section{STUDY OF VISUAL BEHAVIOR OF ANAMORPHIC SIGNALING}

\begin{abstract}
This research proposes an analysis of the horizontal traffic signaling behavior based on anamorphosis according to the vehicle driver shifts. The objective of this study was to diagnose the viability of signaling based on mathematical studies that demonstrated the variation in the height of the anamorphosis in certain distances. For this study, two tables were prepared demonstrating, throughout calculation, the results of the anamorphosis signaling behavior and also a graphic from these values to a better visualization of this variation. The results presented in the graphic demonstrated a gradual increase in the size of anamorphic and sharpest increase after the driver reaches the safety distance. Moreover, it has been observed that the length of the anamorphosis will be much higher than the standard signaling. More studies are considered important for further analysis on the viability of this type of traffic signs.
\end{abstract}

Keywords: anamorphosis, horizontal traffic signs, visual behavior, comparative, anamorphic signaling. 


\section{INTRODUÇÃO}

A ocorrência de acidentes de trânsito é muito frequente no Brasil, sendo esta responsável por grande parte da mortalidade no país. Para melhorar a segurança viária, é preciso que as sinalizações de trânsito passem suas orientações de forma adequada. Pensando nisso, o estudo pretende analisar uma sinalização horizontal com base na técnica da anamorfose.

Segundo o dicionário Houaiss da língua portuguesa (apud FIGUEIREDO, 2009, p.52) anamorfose é:

(...) representação de figura (objeto, cena etc.) de maneira que, quando observada frontalmente, parece distorcida ou mesmo irreconhecível, tornando-se legível quando vista de um determinado ângulo, a certa distância, ou ainda com o uso de lentes especiais ou de um espelho curvo [ou] (...) a deformação de uma imagem obtida por um sistema óptico que permite uma variação da ampliação transversal relativamente a ampliação longitudinal. [Do grego], anamorf(o)- + -ose. anamórphósis 'formado de novo'.

Segundo Semmer, Silva e Neves (2013, p. 66), a anamorfose veio da China, onde os artistas pintavam utilizando espelhos cilíndricos. Essa técnica foi mais explorada durante o período do Renascimento por artistas como Leonardo da Vinci e Hans Holbein. Este segundo, fez a obra mais famosa utilizando essa técnica intitulada "Os Embaixadores".

Atualmente, a anamorfose é aplicada em diversas áreas, principalmente nos meios artísticos e nos meios de publicidade e propaganda. No trânsito, o alongamento das sinalizações horizontais na via é chamado de anamorfose, porém essa distorção não é exatamente uma anamorfose, visto que a técnica explora a tridimensionalidade também.

Sendo assim, esta pesquisa foi elaborada para analisar o comportamento de uma sinalização anamórfica, levando em consideração que esta aponta ter maior percepção por parte dos condutores. (SANTOS, 2014)

O objetivo desta pesquisa é promover um estudo matemático sobre a viabilidade da utilização da anamorfose na sinalização de trânsito, com ênfase na vista lateral da estrutura. Elaborar tabelas e gráficos para melhor compreensão da variação vertical da sinalização anamórfica em relação ao ponto de vista do condutor/veículo.

\section{METODOLOGIA}

A partir do levantamento bibliográfico, foi realizado o estudo matemático do comportamento da anamorfose em relação à distância que a separa do condutor/veículo. Este 
estudo foi baseado na figura abaixo, no qual foi analisada a variação da distorção vertical (h) da anamorfose conforme a distância $(x)$ em que o condutor se encontra dela.

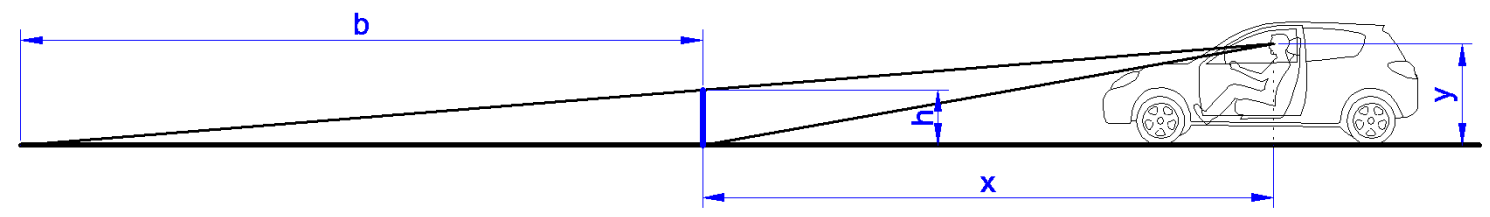

Figura 1. Estudo sinalização. Fonte: SANTOS, 2014.

Seguindo às leis de proporção da semelhança de triângulos temos:

$$
\frac{y}{b+x}=\frac{h}{b}
$$

Substituindo-se os valores da altura do observador (y), distância $(x)$ e altura da anamorfose (h), é possível calcular o tamanho da anamorfose (b), que será o tamanho em que será pintada a sinalização horizontal. A partir disso, é possível saber a altura em que a anamorfose será vista a qualquer distância que se encontre dela. O cálculo foi feito com base na fórmula acima de proporção de semelhança de triângulos e os resultados foram colocados em uma segunda tabela. Nesse caso, os dados y e b serão fixos e será alterado apenas o valor de $x$, gerando assim o valor de h.

E através dos cálculos abaixo, o usuário tem acesso ao ângulo de visão $(\theta)$ do condutor/veículo quando este está submetido à sinalização anamórfica.

$$
\operatorname{arctg} \alpha=\frac{h}{b} \quad \operatorname{arctg} \beta=\frac{y}{x} \quad \theta=\beta-\alpha
$$

Os três primeiros valores $(\mathrm{y}, \mathrm{x}, \mathrm{h})$ podem ser estabelecidos de acordo com as necessidades da pesquisa, por isso são campos que podem ser preenchidas pelo usuário. Quando inseridos esses valores, o restante das tabelas será preenchido automaticamente a partir de cálculos já programados. O Excel permite que sejam aplicadas fórmulas dentro dos seus campos e isso facilita o cálculo e o correto preenchimento das tabelas.

Os dados podem ser inseridos em uma tabela na qual posteriormente mostrará os resultados dos cálculos realizados como a variação da altura da anamorfose conforme o deslocamento do observador.

A partir desses dados das tabelas, foi possível gerar um gráfico para ter uma melhor visualização dessa variação a cada distância. As tabelas e o gráfico foram desenvolvidos no software de criação de planilha chamado Microsoft Office Excel 2010. 
Para esta pesquisa não houve a necessidade de entrevista, pois o intuito foi avaliar a distorção vertical que a anamorfose tem em diversas distâncias. A partir da distância recomendada, foram analisados alguns pontos anteriores e outros posteriores a ela.

\section{RESULTADOS}

A tabela foi preenchida de acordo com os mesmos dados de LIMA, 2006, e foi atribuída a altura da anamorfose de 0,4 metros para comparar o espaço, no caso o comprimento, que as duas formas de sinalizações ocupa no asfalto.

Tabela 1 e 2. Dados gerais e altura da anamorfose em relação à distância.

\begin{tabular}{|l|r|}
\hline \multicolumn{2}{|c|}{ DADOS GERAIS } \\
\hline Altura do Observador $(\mathrm{m})$ & 1,6 \\
\hline Altura Ideal da Anamorfose $(\mathrm{m})$ & 0,4 \\
\hline Distância $(\mathrm{m})$ & 50 \\
\hline Comprimento da Anamorfose $(\mathrm{m})$ & 16,66667 \\
\hline$\alpha$ (em radianos) & 0,0240 \\
\hline$\beta$ (em radianos) & 0,0320 \\
\hline$\theta$ (em radianos & 0,0080 \\
\hline$\theta$ (em graus) & 0,4580 \\
\hline
\end{tabular}

\begin{tabular}{|r|r|}
\hline \multicolumn{2}{|c|}{ GRÁFICO } \\
\hline Distância $(\mathrm{m})$ & Altura da Anamorfose $(\mathrm{m})$ \\
\hline 100 & 0,2286 \\
\hline 90 & 0,2500 \\
\hline 80 & 0,2759 \\
\hline 70 & 0,3077 \\
\hline 60 & 0,3478 \\
\hline 50 & 0,4000 \\
\hline 40 & 0,4706 \\
\hline 30 & 0,5714 \\
\hline 20 & 0,7273 \\
\hline 10 & 1,0000 \\
\hline
\end{tabular}

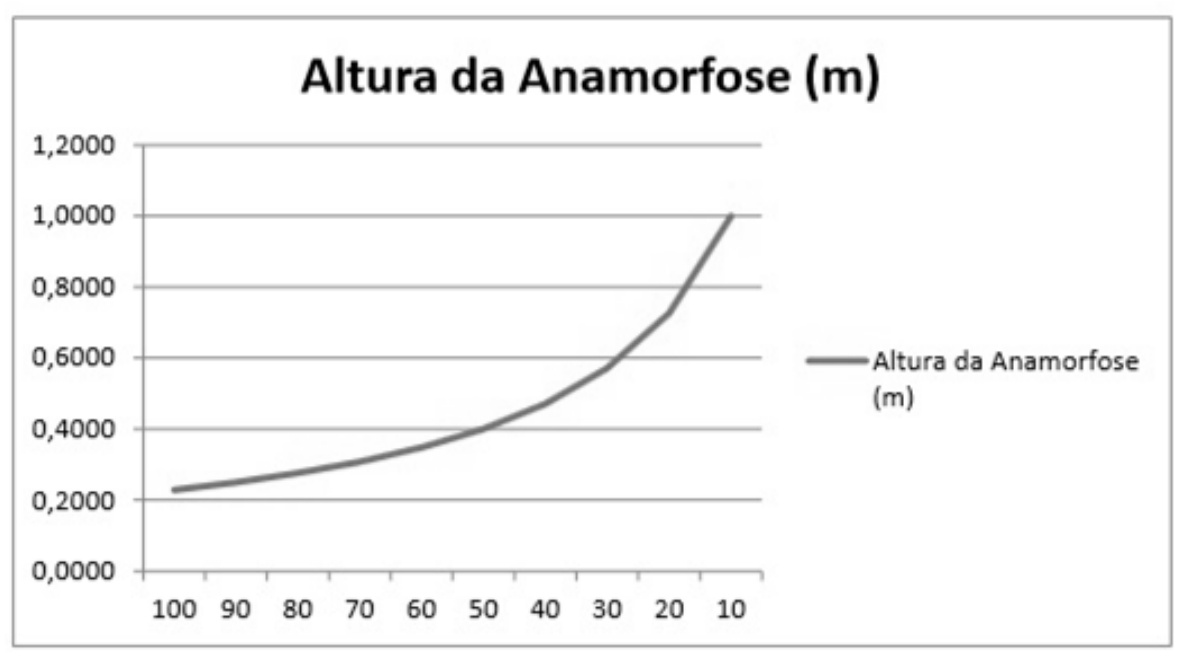

Figura 2. Gráfico da altura da anamorfose em relação à distância.

Analisando o gráfico, a altura da anamorfose cresce gradativamente até a distância de segurança, no caso 50 metros e a partir daí o gráfico eleva de uma forma mais acentuada. Isso mostra que é antes desse ponto já é possível ver a aplicação da anamorfose, mesmo que esteja menor. O condutor consegue perceber a sinalização a uma distância maior que a de segurança e 
assim consegue reduzir a velocidade. No momento em que a distorção se torna mais acentuada este já está atento ao trecho, logo esse aumento da anamorfose não influencia mais em sua alerta.

\section{DISCUSSÃO}

Inicialmente, é recomendada a utilização do Manual Brasileiro de Sinalização de Trânsito do CONTRAN para que a distância de segurança seja inserida corretamente para o cálculo da sinalização anamórfica, pois para cada velocidade máxima permitida na via, há uma distância segura diferente.

É possível notar uma leve constância no gráfico antes da distância de segurança, ponto no qual começa uma subida mais acentuada. Isso nos leva a crer que a vários metros antes do mesmo já é possível visualizar a sinalização, aumentando as chances de o condutor captar a mensagem e seguir com maior atenção naquele trecho.

Segundo LIMA, 2006, na forma tradicional, a pintura teria um comprimento de 5,4 metros aproximadamente e na sinalização anamórfica foi possível ver que será necessário ocupar 16,7 metros. A segunda forma é três vezes maior que a primeira, tornando-a menos viável economicamente. Porém é provável que esse novo tipo de sinalização traga maiores benefícios, como a diminuição dos acidentes de trânsito. Sendo assim, ela teria um melhor custo benefício ao longo dos anos.

\section{CONCLUSÃO}

Através do estudo realizado foi possível observar que o condutor terá uma boa visibilidade da sinalização horizontal de trânsito baseado na anamorfose a uma distância maior que a de segurança. Desta forma, o uso da mesma se torna mais viável. Porém, foi diagnosticado também que, em relação à sinalização tradicional, o anamórfico ocupará comprimentos bem maiores da via, acarretando em um custo maior. Apesar disso, os estudos apontam que há uma boa possibilidade de chamar maior atenção do condutor e isso leva a crer que esse campo de pesquisa ainda pode ser bastante explorado, para que se possa encontrar maiores resultados e compará-los com a sinalização padrão.

\section{REFERÊNCIAS}

FIGUEIREDO, C. Oficina de Anamorfose: Uma nova forma de aprendizagem. OMINIA Humanas [Internet]. 2009 [acesso em 2015 jul 13]; 2(2): 50-59. Disponível em: http://www.fai.com.br/portal/ojs/index.php/omniahumanas/article/view/234. 
CONSELHO NACIONAL DE TRÂNSITO - CONTRAN. Manual Brasileiro de Sinalização de Trânsito: Sinalização horizontal - $\quad$ v.4.(2007). Disponível em: <http://www.denatran.gov.br/publicacoes/show_public.asp?cod=11>. Acesso em: 2014 nov 03.

LIMA R. Anamorfose: A matemática na anamorfose. Disponível em: <http://docslide.com.br/documents/a-matematica-na-anamorfose.html>. Acesso em: 2015 jun 11.

SANTOS, C. Percepção da legenda "devagar": um estudo de usabilidade. In: ERGOdesign 2014.

SUMMER, S.; SILVA, S.; NEVES, M. Anamorfose no Ensino de Geometria. ALEXANDRIA Revista de Educação em Ciência e Tecnologia [Internet]. 2013 [Acesso em 2015 jun 11]; 6(3): 61-86. Disponível em: https://periodicos.ufsc.br/index.php/alexandria/article/download/38010/29010 